\title{
KECENDERUNGAN PENILAIAN PENGGUNA INFORMASI TERHADAP TWEET (KICAUAN) PADA MEDIA SOSIAL TWITTER
}

\author{
Titin Pramiyati \\ Sekolah Teknik Elektro dan Informatika \\ Institut Teknologi Bandung \\ Email: titin.pramiyati@students.itb.ac.id \\ Ayu Purwarianti \\ Sekolah Teknik Elektro dan Informatika \\ Institut Teknologi Bandung \\ Email: ayu@stei.ac.id \\ Iping Supriana \\ Sekolah Teknik Elektro dan Informatika \\ Institut Teknologi Bandung \\ Email: iping@stei.ac.id
}

\begin{abstract}
ABSTRAK
Peran media sosial dalam penyebaran informasi, saat ini sudah berada pada tingkat yang sangat berarti, yang ditandai dengan peningkatan jumlah pengguna media sosial, pemanfaatan media sosial untuk kepentingan penyampaian informasi dibidang politik, hukum, ekonomi, sosial dan bidang lainnya. Media sosial seperti facebook dan twitter merupakan media sosial dengan pengguna terbesar dan memiliki rentang usia pengguna yang sangat lebar. Jumlah pengguna yang besar tidak serta merta menjadikan informasi yang disebarkan melalui media sosial tersebut dapat dipercaya, akan tetapi keberadaan pengguna informasi ini dapat dimanfaatkan untuk menentukan tingkat kepercayaan informasi. Penilaian tingkat kepercayaan informasi, diduga dapat dilakukan dengan berdasarkan pada kesesuaian konteks informasi dengan konteks profil sumber informasi. Merujuk pada dugaan yang dibangun, paper ini membahas hasil survey yang dilakukan untuk mengetahui apakah kesesuaian konteks informasi dengan konteks profil sumber informasi dapat digunakan untuk menentukan tingkat kepercayaan informasi. Survey menggunakan kicauan (tweet) dari beberapa tokoh masyarakat, dengan melibatkan 300 responden yang terdiri dari kelompok Mahasiswa dan kelompok Karyawan. Metode yang digunakan adalah analisis induktif yang menggunakan ukuran numerik dan variabilitas untuk mendeskripsikan kecenderungan penilaian terhadap informasi. Ukuran numerik yang digunakan adalah ukuran tendensi sentral, yaitu dengan menghitung nilai rata-rata, median dan modus. Ukuran variabilitas digunakan untuk mengetahui apakah terdapat penyimpangan yang berarti pada pengukuran numerik yang dilakukan. Hasil survey menunjukkan bahwa kecenderungan responden untuk setuju dengan informasi yang dibuat jika konteks informasi memiliki kesamaan dengan konteks profil sumber informasi. Hasil ini selanjutnya akan dijadikan sebagai dasar dalam pembuatan model penentuan tingkat kepercayaan informasi.
\end{abstract}

Kata kunci: media sosial, twitter, kicauan, analisis induktif, kepercayaan informasi.

\begin{abstract}
The role of social media in the dissemination of information, currently located at a level that means a lot, which is characterized by an increase in the number of users of social media. Most of users of soscial media using this media for distribute information in the field of political, legal, economic, social and other fields. Facebook or Twitter is a social media with the greatest number of users and the users are in a very wide range of age. Having a large number of users do not necessarily make the information disseminated through social media can be trusted by the user. The confidence level of the information can be determined by observing the tendency of ratings given by the users. Therefore, this paper will discuss the tendency of assessment of the trust level of the information provided by the user. The information used in this assessment is the tweet from the account on a social media twitter. Determination of the tendency of the trust value of information using inductive analysis and the use of numeric measures, which is central tendency measurement and variability measurement. Measurements conducted on the results of a survey conducted on a tweet from 30 social media accounts are considered as a source of information, involving 300 respondents were divided into two groups of students and groups of workers. The survey results showed that the tendency of respondents to agree with the information that is made if the context
\end{abstract}


has similarities between context of information and context of resources profile, henceforth, the results of this analysis is used to determine the information trustworthy modeling.

Keywords: social media, twitter, tweet, inductive analysis, information trustworthy.

\section{PENDAHULUAN}

Peran media sosial dalam penyebaran informasi, saat ini sudah berada pada tingkat yang sangat berarti, yang ditandai dengan peningkatan jumlah pengguna media sosial, pemanfaatan media sosial untuk kepentingan penyampaian informasi dibidang politik, hukum, ekonomi, sosial dan pemanfaatn bidang lainnya. Kawasan Asia adalah kawasan dengan pengguna internet terbesar di dunia dengan jumlah 48,2\% [Sumber: http://www.internetworldstats.com, 15 Maret 2016], seperti terlihat pada Gambar 1. Indonesia sebagai bagian dari kawasan Asia, menyumbang 4,8\% pengguna dengan jumlah pengguna media sosial Facebook sebesar 78.000.000 pengguna, dan jumlah pengguna yang melakukan penetrasi adalah sebesar $30 \%$ dari populasi Indonesia.

\section{Internet Users in the World by Regions November 2015}

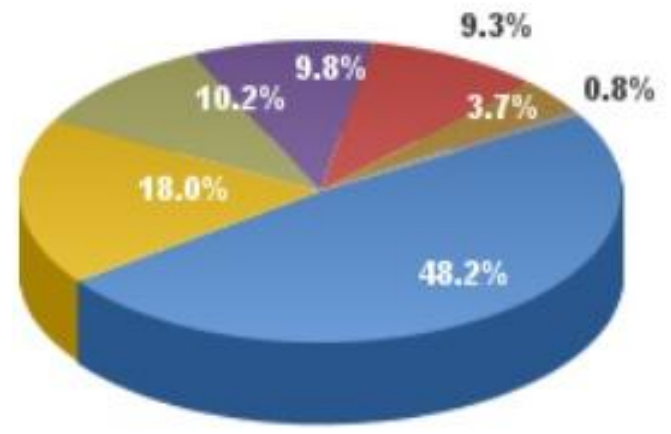

Asia $\mathbf{4 8 . 2} \%$

Europe $18.0 \%$

Lat Am / Carib. $10.2 \%$

Africa $9.8 \%$

North America $\mathbf{9 . 3} \%$

Middle East $3.7 \%$

Oceania / Australia $0.8 \%$

\section{Source: Internet World Stats - www.internetworldstats.com/stats.htm Basis: $3,366,261,156$ Internet users on November 30,2015 Copyright @ 2015, Miniwatts Marketing Group}

\section{Gambar 1. Pengguna internet dunia}

Jumlah pengguna Twitter di Indonesia pada tahun 2010 berada pada urutan atas bersama negara lain, dengan jumlah $20.8 \%$ pengguna yang mengakses Twitter.com baik dari rumah ataupun tempat bekerja [Sumber: https://www.comscore.com, 15 Maret 2016]. Jumlah pengguna yang besar tidak serta merta menjadikan informasi yang disebarkan melalui media sosial tersebut dapat dipercaya oleh penggunanya. Kualitas informasi, kepercayaan informasi dan kepercayaan sumber informasi menjadi persoalan penting sejak teknologi web dimanfaatkan untuk mendapatkan informasi. Kualitas informasi juga menjadi perhatian penting bagi DoD-USA, hal ini terlihat dengan dituangkan pernyataan bahwa informasi yang kuat adalah informasi yang terpercaya dalam strategi pertahanannya [1].

Kebutuhan atas informasi yang dapat dipercaya menjadi motivasi pengembangan sistem untuk menentukan nilai kepercayaan informasi dan sumber informasi, sehingga pengguna informasi dapat menentukan informasi yang patut untuk dipercaya dan informasi yang diabaikan [2], dan mendapatkan kebenaran isi informasi [3]. Informasi yang dipercaya dapat diperoleh berdasarkan pada kepercayaan yang dimiliki oleh sumber informasi [2], terdapat dua jenis penilaian kepercayaan yaitu direct trust (kepercayaan langsung) dan recommended trust [4], direct trust adalah penilaian kepercayaan berdasarkan pada interaksi langsung yang terjadi. Penilaian kepercayaan langsung dapat ditentukan berdasarkan pada konteks [4] dan trust scope [5]. S.Ibotombi Singh dan Smriti K. Sinha [4] menyatakan bahwa kepercayaan dapat dibangun berdasarkan pada context-sensitive, transferable, dynamic dan history-based. Penggunaan context-sensitive dalam membangun kepercayaan dapat menjadikan suatu agent dipercaya pada satu konteks, dan tidak dipercaya pada konteks lain.

Berdasarkan pada beberapa penelitian yang telah dilakukan berkaitan dengan penentuan tingkat kepercayaan, konteks dan profil sumber informasi dapat digunakan dalam penentuan tingkat kepercayaan informasi. Cara yang dilakukan untuk menentukan tingkat kepercayaan yaitu dengan memperhatikan kesesuaian konteks informasi dengan konteks profil sumber informasi, untuk mengetahui apakah cara ini 
dapat digunakan, paper ini akan membahas hasil analisis terhadap hasil survey yang dilakukan untuk mengetahui apakah kesesuaian konteks informasi dengan konteks profil sumber informasi dapat digunakan untuk menentukan tingkat kepercayaan informasi.

Metode yang digunakan adalah analisis induktif yang menggunakan ukuran numerik dan variabilitas untuk mendeskripsikan kecenderungan penilaian terhadap informasi. Ukuran numerik yang digunakan adalah ukuran tendensi sentral, yaitu dengan menghitung nilai rata-rata, median dan modus. Ukuran variabilitas digunakan untuk mengetahui apakah terdapat penyimpangan yang berarti pada pengukuran numerik yang dilakukan. Analisis menggunakan hasil pengolahan data survey dengan jumlah responden yang dilibatkan adalah 300 orang, dan informasi yang disurvey merupakan tweet (kicauan) yang diambil dari 30 akun Twitter. Nilai yang diberikan merupakan hasil kompilasi responden dengan memperhatikan isi informasi dan profil dari sumber informasinya.

Hasil analisis berupa kesimpulan yang dibuat berdasarkan data survey yang menunjukkan kecenderungan penilaian responden terhadap informasi, konsistensi penilaian yang dilakukan, dan penyimpangan penilaian responden. Kesimpulan yang didapat, selanjutnya akan digunakan sebagai pembanding hasil penentuan tingkat kepercayaan informasi menggunakan model sistem kepercayaan informasi.

\section{METODOLOGI PENELITIAN}

Penelitian, pada umumnya berupa penelitian eksplorasi, deskriptif, atau pengujian hipotesa, tergantung pada tahap apa pengetahuan terhadap penelitian yang akan dikembangkan [6]. Penelitian deskriptif mencoba menggambarkan situasi yang ingin diketahui melalui pertanyaan siapa, apa, kapan, dimana dan bagaimana [7], terdapat dua manfaat penggunaan studi deskriptif, yaitu sebagai dasar dalam pengambilan keputusan dan untuk mengenali distribusi dan perilaku data [8].

Penelitian deskriptif dilakukan agar dapat mendeskripsikan karakteristik dari variabel yang diinginkan pada situasi tertentu, dan tujuan dari penelitian deskriptif adalah memberikan kepada peneliti gambaran atau deskripsi aspek yang relevan dari fenomena yang dipelajari dari sudut pandang individu, kelompok dalam organisasi atau sudut pandang lainnya. Penelitian deskriptif yang menyajikan data dalam bentuk yang berarti, akan membantu dalam pemahaman karakter dari suatu kelompok dalam situasi tertentu, berpikir secara sistematis tehadap beberapa aspek dalam situasi tertentu, memberikan ide-ide untuk penelitian lebih lanjut, dan membantu membuat keputusan tertentu yang sederhana. Penelitian deskriptif menjadi penting dalam banyak situasi, oleh karenanya data kualitatif yang diperoleh melalui wawancara, data kuantitatif seperti frekuensi atau nilai tengah dan standard deviasi menjadi penting untuk penelitian deskriptif.

Merujuk pada tujuan penelitian yang dilakukan, yaitu mendapatkan profil kecenderungan penilaian kepercayaan informasi, maka penelitian ini menggunakan metodologi penelitian yang sesuai dengan tujuan penelitian deskriptif. Penelitian deskriptif ini terdiri dari beberapa Tahap, yaitu; pengumpulan data kicauan, survey, pengolahan data, dan analisis. Pengumpulan data kicauan yang akan dinilai diambil dari 30 pemilik akun di media sosial Twitter. Survey yang dilakukan melibatkan 300 responden, 30 sumber informasi dengan sejumlah tweet yang dibuat oleh masing-masing sumber informasi. Sehingga setiap sumber informasi akan dinilai oleh 10 responden. Responden yang dilibatkan pada survey ini terdiri dari 2 kelompok, yaitu kelompok mahasiswa dan pekerja, setiap sumber informasi akan dinilai oleh 5 orang mahasiswa dan 5 orang pekerja.

Mekanisme pemberian nilai yang dilakukan oleh responden adalah sebagai berikut: responden akan menilai setiap tweet yang dibaca dengan nilai kualitatif sangat setuju, setuju, cukup setuju, tidak setuju, sangat tidak setuju, yang diwakili secara terurut dengan nilai 5,4,3,2,1. Setiap penilaian terhadap tweet, responden diharuskan untuk memperhatikan profil sumber informasi (user profile) yang terdapat pada Bio Twitter, agar nilai yang diberikan oleh responden untuk tiap tweet dilakukan dengan memperhatikan konteks dari tweet dan kontek dari profil sumber informasi (user profile).

Hasil yang diperoleh dari survey, digunakan dalam tahap pengolahan data untuk menentukan tingkat kepercayaan sumber informasi dengan cara mendeskripsikan hasil survey. Deskripsi yang dilakukan menggunakan ukuran numerik yaitu ukuran tendensi sentral dan ukuran variabilitas. Ukuran tendensi sentral digunakan untuk mengukur kecenderungan suatu himpunan data yang mengelompok atau memusat dalam nilai numerik tertentu. Metode yang digunakan untuk mengukur tendensi sentral adalah dengan menghitung rata-rata (mean), median, dan modus. Rata-rata hitung diperoleh dengan menggunakan persamaan Error! Reference source not found.:

$\bar{X}=\left(2_{i=1}^{n} x_{i}\right) / n$ 
Ukuran variabilitas adalah suatu ukuran yang mengukur sebaran data, dengan memperhatikan seberapa jauh data menyimpang dari nilai rata-ratanya. Untuk mendapatkan ukuran penyimpangan nilai rata-rata digunakan ukuran standar deviasi (s) yang diperoleh dari persamaan Error! Reference source not found. berikut:

$s=\sqrt{\frac{\sum_{i=1}^{n}\left(x_{i}-\bar{x}\right)^{2}}{n-1}}$

Jika ukuran standar deviasi nilainya relatif besar berarti data yang digunakan memiliki variabilitas tinggi, dan bila standar deviasi relatif kecil, memberi arti data yang digunakan mengelompok di seputar nilai rata-rata dan penyimpangannya kecil. Setiap informasi yang disurvey, akan dihitung nilai rata-rata, median, modus, dan standar deviasi untuk mendapatkan kecenderungan nilai yang diberikan oleh responden untuk setiap informasi. Kecenderungan nilai yang diberikan digunakan untuk menentukan apakah informasi yang dibuat oleh sumber informasi dipercaya atau tidak. Hasil pengolahan data ini selanjutnya digunakan untuk melakukan analisis hasil dengan menggunakan metode analisis induktif.

Analisis induktif yang digunakan pada penelitian ini dimaksudkan untuk mendapatkan kesimpulan yang didasarkan dari hasil survey penilaian kepercayaan informasi. Kesimpulan yang dihasilkan akan menjadi dasar dalam pembangunan mekanisme penghitungan nilai kepercayaan informasi menggunakan nilai kepercayaan sumber informasi.

\section{HASIL PENELITIAN DAN PEMBAHASAN}

Informasi yang dinilai responden adalah kicauan yang dibuat oleh pengguna media sosial Twitter. Jumlah tweet yang digunakan pada penelitian ini sebanyak 242 tweet dari 7 sumber informasi pengguna Twitter. Selain tweet, penelitian ini juga menggunakan data profil milik sumber informasi yang terdapat pada Bio Twitter. Berikut ini adalah pengukuran kepercayaan informasi terhadap informasi yang dibuat oleh sumber informasi dengan username @contoh1 (data disamarkan) dengan data informasi yang digunakan dalam survey berjumlah 37 informasi. Masing-masing tweet kemudian dinilai oleh responden, untuk selanjutnya dihitung nilai rata-rata (mean score) tiap tweet dengan menggunakan persamaan Error! Reference source not found., seperti terlihat pada Tabel 1. Profil sumber informasi memiliki konteks politik dan hukum, sebagaimana tertera pada data yang diambil dari Bio Twitter sumber informasi pada Gambar 2. dibawah ini.

"Account name: Contoh1 : User name: @contoh1 (Guru Besar FH-UII Yogyakarta, Ketua Mahkamah Konstitusi 2008-2013, Ketua Presidium KAHMI, Ketua Dewan Kehormatan ISNU, Ketua PP IKA-UII, Ketua Dewan Pleno Press Code, Menteri Pertahanan RI 2000-2001, Rektor Universitas Islam Kadiri 2003-2006.")

\section{Gambar 2. Bio Twitter @ contoh1}

Penentuan konteks hukum terhadap profil sumber informasi @ contoh1 didasarkan pada data yang berisi “Guru Besa FH-UII”, dan "Ketua Mahkamah Konstitusi”. Konteks politik yang terdapat pada profil sumber informasi didasarkan pada profil data dengan isi "Menteri Pertahahan RI", karena diasumsikan semua jabatan yang berkaitan dengan eksekutif, yudikatif dan legislatif di pemerintahan adalah jabatan politik.

Tweet Q1_3 yang tertera pada Tabel 1., merupakan informasi dengan konteks politik dan konteks hukum. Konteks politik yang terdapat pada informasi ini ditentukan berdasarkan pada isi informasi yang membahas tentang lembaga KPK, yaitu salah satu lembaga yudikatif. Penentukan konteks hukum pada informasi ini dikarenakan informasi ini juga membahas permasalahan hukum yang diwakili dengan kata “adili". Nilai rata-rata informasi Q1_3 adalah 4.2, dengan nilai Median adalah 4 (setuju), dan nilai Modus adalah 4 (setuju). Perolehan ukuran tendensi sentral tersebut menunjukkan penilaian responden cenderung setuju dengan informasi Q1_3 yang dibuat oleh sumber informasi. 
Tabel 1. Penilaian tweet dengan konteks hukum dan politik oleh responden pada saat survey

\begin{tabular}{clccc}
\hline \multicolumn{1}{c}{ Tweet } & \multicolumn{1}{c}{ Kategori Nilai } & Total & Mhs & Pekerja \\
\hline Q1_3. Agar tak dnilai politis @ KPK RI hrs & Sangat tidak setuju & & & \\
segerakan 2 hal. 1) Cln menteri lain & $(1.0)$ & 0 & 0 & 0 \\
yg distabilo merah sgr di-jdkan & Tidak Setuju (2.0) & 0 & 0 & 0 \\
TSK. 2) Yg sdh lama TSK sgr adili & Cukup setuju (3.0) & 1 & 1 & 0 \\
& Setuju (4.0) & 6 & 4 & 2 \\
& Sangat setuju (5.0) & 3 & 0 & 3 \\
& Tidak tahu & 0 & 0 & 0 \\
& Mean score & $\mathbf{4 . 2}$ & $\mathbf{3 . 8}$ & $\mathbf{4 . 6}$ \\
\hline
\end{tabular}

Kecenderungan responden untuk menyetujui informasi, diasumsikan karena konteks informasi memiliki kesamaan konteks dengan beberapa data profil sumber informasi, seperti profil sebagai "Guru Besar FH-UII" mewakili konteks hukum, dan profil "Menteri Pertahanan" dan "Mahkamah Konstituasi" dapat diasumsikan sebagai konteks politik. Hasil penilaian yang dilakukan oleh responden terhadap tweet lain dari sumber informasi yang sama menunjukkan perolehan nilai rata-rata yang berbeda, hal ini dikarenakan tweet Q1_6 pada Tabel 2., hanya memiliki konteks hukum. Penentuan konteks hukum didasarkan pada isi informasi berkaitan dengan bidang hukum, yang ditunjukkan dengan kata "hukum" yang terdapat dalam tweet. Nilai rata-rata dari informasi (a) adalah 4,1 dengan nilai median dan modus adalah 4 (setuju).

Tabel 2. Penilaian tweet dengan konteks hukum oleh responden pada saat survey

\begin{tabular}{lllccc}
\hline \multicolumn{1}{c}{ Tweet } & \multicolumn{1}{c}{ Kategori Nilai } & Total & Mhs & Pekerja \\
\hline Q1_6. & POLRI (1) Dari sudut hukum, & Sangat tidak setuju (1.0) & 0 & 0 & 0 \\
pengusulan BG oleh Presiden dan & Tidak Setuju (2.0) & 0 & 0 & 0 \\
penetapan BG sbg TSK oleh KPK & Cukup setuju (3.0) & 1 & 1 & 0 \\
sama benarnya. Keduanya punya & Setuju (4.0) & 7 & 4 & 3 \\
dasar hukum. & Sangat setuju (5.0) & 2 & 0 & 2 \\
& Tidak tahu & 0 & 0 & 0 \\
\hline
\end{tabular}

Contoh informasi lain yang digunakan dalam survey terdapat pada Tabel 3, yaitu tweet Q1_28 dengan konteks agama. Responden memberi nilai informasi ini dengan nilai rata-rata adalah 2,4. Nilai median dan modus dari informasi ini adalah 2 (tidak setuju), yang memberi arti bahwa kecenderungan responden terhadap informasi ini adalah "tidak setuju". Analisis terhadap perolehan nilai rata-rata informasi ini, dikarenakan data profil sumber informasi tidak terdapat profil dengan konteks agama.

Tabel 3. Informasi dengan konteks Agama

\begin{tabular}{clccc}
\hline \multicolumn{1}{c}{ Tweet } & \multicolumn{1}{c}{ Kategori Nilai } & Total & Mhs & Pekerja \\
\hline Q1_28. Itu ada tokoh hebat namanya & Sangat tidak setuju (1.0) & 2 & 1 & 1 \\
@ nihasrinP yang mengatakan & Tidak Setuju (2.0) & 4 & 3 & 1 \\
seluruh ulama di Pulau Jawa tak & Cukup setuju (3.0) & 2 & 1 & 1 \\
ada yang tahu apa itu agama. & Setuju (4.0) & 2 & 0 & 2 \\
Kita tunggu fatwanya & Sangat setuju (5.0) & 0 & 0 & 0 \\
& Tidak tahu & 0 & 0 & 0 \\
& Mean score & 2,4 & 2 & 2,8
\end{tabular}

Hasil perhitungan nilai rata-rata dari 37 informasi yang dibuat oleh sumber informasi @contoh1 adalah 3.68, yang menunjukkan kecenderungan responden adalah cukup setuju. Ukuran penyimpangan digunakan nilai standar deviasi yang dihitung menggunakan nilai rata-rata setiap kicauan sebagai data $x_{i}$ dan nilai rata-rata dari keseluruhan kicauan sebagai $\ddot{x}$, dengan jumlah data sebesar $n=37$, maka menggunakan rumus deviasi standar $(s)$ pada persamaan (2), diperoleh hasil 0.07412. Nilai standar deviasi yang diperoleh relatif kecil, artinya data yang survey mengelompok diseputar nilai rata-ratanya.

Berdasarkan pada data survey menggunkan data sumber informasi @ contoh1, perolehan nilai ratarata tweet dengan konteks hukum dan politik berada pada rentang nilai 3-5, sementara perolehan nilai rata-rata tweet dengan konteks lain, seperti tweet yang berisi gurauan (joke), konteks olahraga, dan konteks agama memiliki nilai rata-rata di bawah nilai 3. Meskipun demikian, tidak semua informasi 
dengan konteks selain politik dan hukum mendapat nilai kurang dari 3, seperti tweet (Q1_23) berikut yang berisi "Winny carita presenter TVOne yg berdarah Madura. Cantik, cerdas, tajam --)= @ winnycharita Grab it fast: " yang memperoleh nilai rata-rata 3.3. Memperhatikan perolehan nilai ratarata dari setiap tweet yang dibuat, dapat dinyatakan bahwa nilai rata-rata dapat digunakan sebagai nilai kepercayaan informasi, walaupun terdapat beberapa penyimpangan penilaian yang inkonsisten dari responden, seperti penilaian pada tweet Q1_23.

Pembahasan hasil survey terhadap tweet yang dibuat oleh sumber informasi dengan username@contoh2, seorang yang berprofesi di bidang pertahanan atau militer seperti yang tertera pada data profil yang terdapat pada Bio Twitter (Gambar 3) berikut ini.

“Account name: Contoh2 : User name: @ contoh2 (Menteri Pertahanan 27 Oktober 2014, Kepala Staf Angkatan Darat 2002-2005, Panglima Kostrad.)"

\section{Gambar 3. Bio Twitter @ contoh2}

Perolehan nilai rata-rata yang tertera Tabel 4., memperlihatkan nilai rata-rata yang diberikan responden untuk tweet dengan konteks militer memperoleh nilai rata-rata diatas angka 4 (setuju), seperti perolehan nilai rata-rata untuk tweet Q8_7 yang berisi “ Kopassus juara menembak jitu Keahlian menembak sasaran secara tepat menjadi syarat mutlak anggota pasukan elite seperti Kopassus". Hal ini menunjukkan responden percaya terhadap informasi yang memiliki kesesuaian konteks dengan profil sumber informasi. Perolehan nilai rata-rata untuk tweet yang tidak memiliki kesamaan konteks dengan profil sumber informasi mendapatkan nilai di bawah 3 (cukup setuju), seperti perolehan nilai rata-rata pada tweet Q8_23 yang berisi "Menurut saya aNegara ISRAEL memiliki keunikan yang Tidak Di Miliki Oleh kebanyakan negara", hal ini dikarenakan informasi yang dibuat tidak sesuai dengan kompetensi yang dimiliki oleh sumber informasi.

Tabel 4. Nilai rata-rata tweet yang dibuat oleh akun @ contoh2

\begin{tabular}{cccccccc}
\hline \multirow{2}{*}{ Tweet } & \multicolumn{3}{c}{ Nilai Rata-rata } & \multirow{2}{*}{ Tweet } & \multicolumn{3}{c}{ Nilai Rata-rata } \\
\cline { 2 - 3 } Q8_1 & Mahasiswa & Pekerja & Total & & Mahasiswa & Pekerja & Total \\
\hline Q8_2 & 2,4 & 2,6 & 2,5 & Q8_17 & 4,2 & 4,4 & 4,3 \\
Q8_3 & 3 & 2,8 & 2,9 & Q8_18 & 4,4 & 4,6 & 4,5 \\
Q8_4 & 3,2 & 3 & 3,1 & Q8_19 & 4 & 4,4 & 4,2 \\
Q8_5 & 3,8 & 3,6 & 3,4 & Q8_20 & 4,2 & 4,2 & 4,2 \\
Q8_6 & 3,2 & 3 & 3,4 & Q8_21 & 4,4 & 4 & 4,2 \\
Q8_7 & 4,8 & 4,4 & 3,3 & Q8_22 & 4,2 & 4 & 4,1 \\
Q8_8 & 4,6 & 4,4 & 4,7 & Q8_23 & 2,2 & 2 & 2,1 \\
Q8_9 & 4,6 & 4,4 & 4,5 & Q8_24 & 2 & 2 & 2 \\
Q8_10 & 4,6 & 4,4 & 4,5 & Q8_26 & 2,4 & 2,2 & 2,3 \\
Q8_11 & 4,8 & 4,8 & 4,8 & Q8_27 & 2,6 & 2,6 & 2,6 \\
Q8_12 & 4,4 & 4,2 & 4,3 & Q8_28 & 3 & 2,4 & 2,7 \\
Q8_13 & 3,2 & 3 & 3,1 & Q8_29 & 2,6 & 2,8 & 2,7 \\
Q8_14 & 4,6 & 4,4 & 4,5 & Q8_30 & 2 & 2,2 & 2,1 \\
Q8_15 & 4,2 & 4,8 & 4,5 & Q8_31 & 2,6 & 2,8 & 2,7 \\
Q8_16 & 4,6 & 4,4 & 4,5 & Q8_32 & 2,8 & 2,4 & 2,6 \\
\hline
\end{tabular}

Berdasarkan pada grafik perolehan nilai rata-rata pada Gambar 4., memperlihatkan grafik penilaian yang diberikan oleh responden (kelompok Mahasiswa dan Pekerja) sangat dipengaruhi oleh konteks informasi yang dibuat dan profil milik sumber informasi. Kesamaan penilaian yang diberikan oleh kedua kelompok menunjukkan bahwa data profil sumber informasi yang menunjukkan konteks seseorang dengan jelas, akan memberi dampak berarti ketika sumber informasi membuat informasi dengan konteks yang sesuai atau tidak sesuai dengan konteks profil yang dimiliki. 


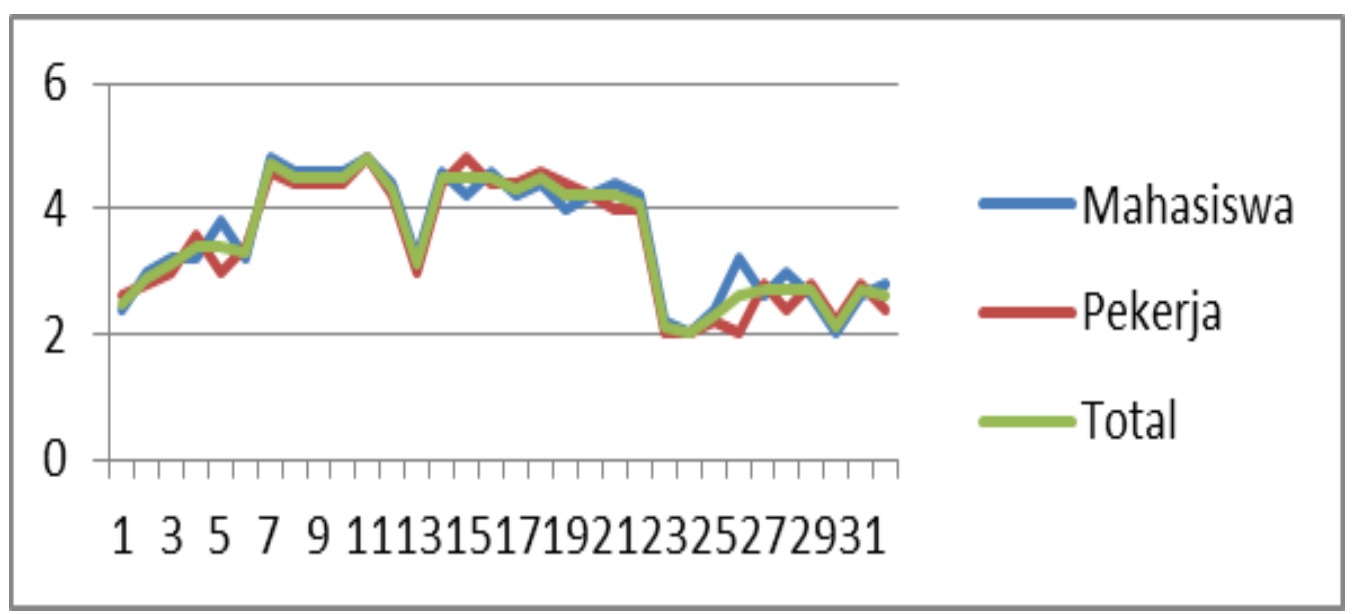

Gambar 4. Grafik perolehan nilai rata-rata akun @ contoh2

Nilai rata-rata yang diperoleh dari 32 informasi yang disurvey adalah 3.51, yang menunjukkan kecenderungan responden terhadap informasi yang dibuat oleh sumber informasi @ contoh2 adalah cukup setuju. Deviasi standar (s) dari data sampel ini relatif kecil yaitu sebesar 0.166878 , sehingga dapat dikatakan penyimpangan datanya juga kecil.

\section{KESIMPULAN}

Pengguna informasi dapat menentukan kepercayaan informasi dengan berdasarkan pada konteks informasi dan konteks yang terdapat pada profil sumber informasi, dengan memperhatikan kesesuaian konteks antara informasi dengan konteks profil sumber informasinya. Penentuan kepercayaan informasi ini akan berhasil dan menuntut pengguna dalam pemilihan informasi, jika pengguna selalu konsisten dan dapat menelaah setiap konteks yang ditemukan pada informasi dan teliti dalam menentukan konteks pada profil sumber informasinya. Sebaliknya, jika pengguna tidak konsisten dan tidak dapat menentukan konteks yang terdapat pada informasi dan profil sumber informasi, maka hasil penentuan kepercayaan informasi akan bias dan kemungkinan kesalahan penentuan dapat terjadi.

Inkonsistensi dan kesalahan penilaian yang mungkin timbul dalam menentukan kepercayaan informasi oleh pengguna informasi, dapat diatasi dengan membangun sebuah sistem penilaian kepercayaan informasi otomatis, dengan proses pencarian kesesuaian konteks informasi dan konteks profil sumber informasi sebagai salah satu proses untuk menghasilkan nilai kepercayaan sumber informasi dan selanjutnya digunakan untuk menentukan nilai kepercayaan informasi. Penentuan konteks informasi dan konteks profil sumber informasi sesuai dengan kategori konteks yang akan digunakan dapat dijadikan penelitian berikutnya.

\section{UCAPAN TERIMA KASIH}

Penulis mengucapkan terimkasih kepada Universitas Pembangunan Nasional "Veteran" Jakarta (UPNVJ) yang telah memberikan dana survey untuk mendukung penelitian ini.

\section{DAFTAR PUSTAKA}

[1] Department of Defense-USA. 2008-2009. "Department of Defense Information Management \& Information Technology Strategic Plan"

[2] Gil Y, Ratnakar V. 2002. "Trusting Information Sources One Citizen at a Time". Proceeding First Int Semant Web Conf.

[3] Javanmardi S, Lopes CV. 2007. "Modeling Trust in Collaborative Information Systems". Evolution (N Y).

[4] Singh SI, Sinha SK. 2009. "A New Trust Model based on Social Characteristics and Reputation Mechanisms using Best Local prediction Selection Approach". Int Conf New Trends Inf Serv Sci.

[5] Thirunarayan K, Anantharam P, Henson CA, Sheth AP. 2010. "Some Trust Issues in Social Networks and Sensor Networks". IEEE. 978-1-4244:573-80.

[6] Sekaran Uma, Bougie Roger. (2010). Research Methods for Businees : A Skill Building Approach. John Wiley \& Sons Ltd.

[7] Zikmund William G., Babin Barry J., Carr Jon C., Griffin M. (2010). Business Research Methods. South-Western Cengage Learning 
[8] Kuncoro Mudrajad. (2011). Metode Kuantitatif. Edisi Keempat, UPP STIM YKPN 